\title{
Fuzzy Decision in Airplane Speed Control
}

\author{
Agnaldo V. Lovato, Ernesto Araujo, Member, IEEE, José D. S. da Silva
}

\begin{abstract}
A fuzzy decision system for helping air-traffic experts in controlling airplane velocities and in keeping an airplane flight within several constraints established to air lane sections is proposed in this paper. Automatic systems for airtraffic control are essential due to the ever increasing number of airplanes flying all over the world, the amount of environmental and airplane constraints and the necessity to guarantee the safety both for flights and for air-traffic control operators. The proposed system uses Mamdani direct inference method. Results show the effectiveness of the developed fuzzy system in controlling the airplane velocity to achieve the desired performance and encourage the adequacy of the system to include several different variables usually employed in airtraffic control.
\end{abstract}

\section{INTRODUCTION}

$\mathrm{T}_{\mathrm{c}}^{\mathrm{h}}$ he increasing worldwide airplane traffic demands new control solutions for air-traffic control engineers that may guarantee the safety in the thousand of daily flights all over the world [5]. New air-traffic knowledge management system is vitally important for the safety and efficiency of future air travel and so, new automatic technological solutions to face safety issues in the world air-traffic control is necessary [3][19].

Air-traffic control capacity is directly related to the number of airplanes a controller may simultaneously supervise and manage [18]. Flight controllers need new systems to deal with several different variables that dynamically change along the day. Many of these variables are directly related to atmospheric conditions, airplanes, airports, control sectors etc., that is, every environment, object or individual related to control centers that may influence decision-making [3][4]. Control centers compose the international air-traffic control structure by dealing with a number of sectors with the corresponding airplane traffic (IMA 100-12, 1999) as it is illustrated in Fig. 1, where the dot lines represent air lanes that may cross-different sectors and may even enter other control centers.

Manuscript received January 30, 2006. This work was supported in part by the CNPq under Grant.

A. V. Lovato is with the Instituto Nacional de Pesquisas Espaciais INPE, at the Computer Sci. and Applied Math. Associated Lab - LAC, Av. dos Astronautas, 1758 - Sao Jose dos Campos (SP) - Brasil - 12.227-010 (phone: 55 (12) 3945 6315; fax: 55 (12) 3941 1884; e-mail: agnaldo@lac.inpe.br).

E. Araujo is with the Instituto Nacional de Pesquisas Espaciais - INPE, at the Integration and Testing Laboratory - LIT, (e-mail: ernesto@lit.inpe.br).

J. D. S. da Silva is with the Instituto Nacional de Pesquisas Espaciais INPE, at the Computer Sci. and Applied Math. Associated Lab - LAC, (email:demisio@lac.inpe.br).

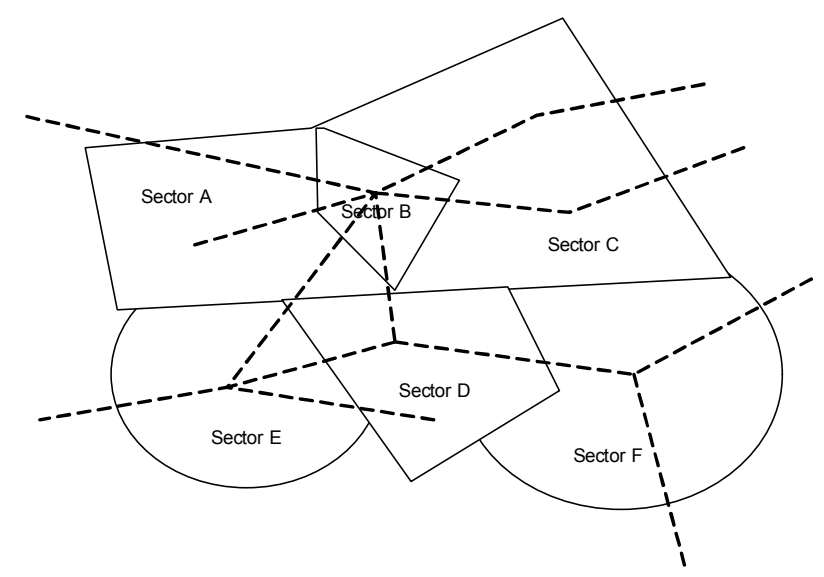

Fig. 1 - Control centers and the corresponding designated control sectors.

Different phases of a flight plan, including taxing, take off, exiting the airport area, navigation to destiny, approximation area (landing), taxing to airport fingers are presented in Fig. 2. Each of these phases requires specific functions that define attitudes to be adopted for safe airplane traffic, under the existing rules imposed by the air-traffic control organizations [16] [19].

Usually air-traffic controllers are in charge of taking off and landing authorizations, distance among airplanes on the same air lane, altitude and velocity control, etc., all of which are directly involved with traffic safety. Thus human operators need to carefully analyze the whole of airplane traffic within a sector and/or a center to decide the best action to pass on to airplane pilots [17]. Such decisions are mainly based on the operator's expertise in managing airports and airplanes and become difficult under heavy airtraffic conditions [15]. Thus, in increasing air-traffic conditions, decision support systems may be an alternative to enhance the confidence in decision-making by human operators [11].

Finding out devices and mechanisms for supporting airtraffic controllers in their tasks of managing airplanes has been a research issue of great interest in the literature. For instance, Matos describe the main problems when managing airplane routes (re-routing) as well as how a decision support system should be employed to assist operators in strategic activities [14]. In this sense, Nogami presents a real-time decision-support system and learning machines working in cooperation in such a way that artificial neural network method is used to schedule airplanes [10]. Thus, for situations like that, a feasible solution is to consider intelligent systems [8]. 
This paper addresses the problem of aircraft velocity control for landing perimeter system based on fuzzy decision support systems. The use of a fuzzy system and approximate reasoning applied to decision and control problem has been a research issue [1][9] and it is an alternative approach for finding out an air-traffic control strategy for dealing with this problem. A fuzzy system accesses fuzzy logic to determine the action being employed on a controlled system and can be used to imitate human behavior by carrying out methodologies and techniques used by human experts. Thus, knowledge and rules employed to compose decision mechanisms by air-traffic control experts can be brought out and, then, be translated into an intuitive natural language in a supervisory system (fuzzy decision support system) [12] [13]. Thus, this fuzzy system is employed to help air-traffic controllers to make an airplane fly within the velocity limits established to an air lane sector, considering the existing environmental and airplane constraints.

\section{FUZZY DECISION SYSTEM FOR AIR-TRAFFIC CONTROL}

In some sections of an air lane, an airplane may not surpass a specific maximum velocity. In particular, this paper focuses in the airplane velocity control at landing and taking off, respectively, phases 2,6 and 3,5 of the flight plan (Fig. 2).

This sort of problem relies on specific and distinct constrains. For instance, there are circumstances in which the airplane may not reduce its velocity when required to achieve a required velocity due to technical features (physical limitations) or even due to existing operating problems prompted by the air-traffic control center. There also are cases in which airplanes are not capable of increasing its velocity as required due to constrain in airplane engines. Consider, for instance, the velocity standards within an air lane section for the Standard Terminal Arrival Routes (STAR) GURU 27 to approximate Guarulhos' airport in Sao Paulo, Brazil, as depicted in Fig. 3. At the section entrance - the FAET waypoint - the maximum velocity is $250 \mathrm{Knots}(\mathrm{Kt})$ and at the exit terminal - the PONY waypoint - the maximum velocity is $210 \mathrm{Kt}$.

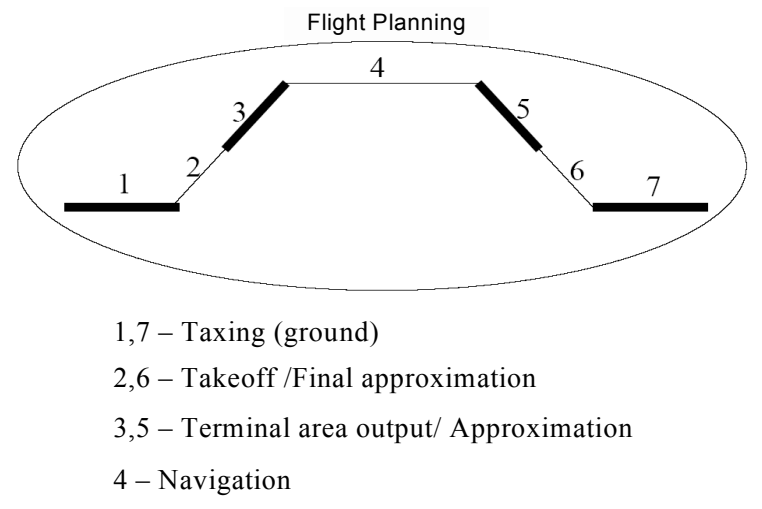

Fig. 2 - Flight plan phases.

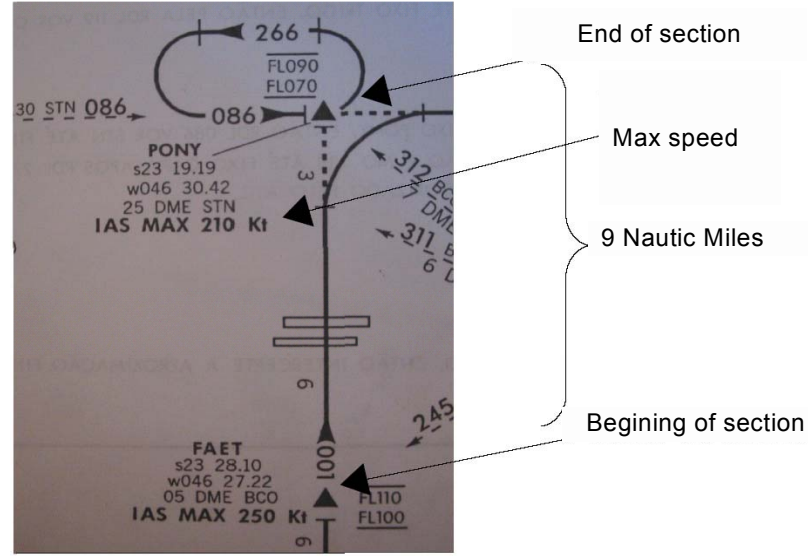

Fig. 3 Real velocity standard for air lane section velocity limits.

The distance form one point to another is 9 nautics miles. It is worth mentioning that there is also additional information in this figure that is not considered for the purposes addressed here.

In this paper a new mechanism is developed to provide information to air-traffic controllers for helping them to decide upon specific actions to be passed over to pilots. This approach embraces a fuzzy decision support system to control an airplane velocity within the maximum thresholds defined for air lane section waypoints. Individual features of each airplane are taking into account when defining a velocity increase or a velocity reduction to fulfill the ideal velocity at a certain instant. The system may be used to simulate different conditions as well as to help human operators verify if the airplanes are flying at the allowed velocities. In doing so, proposed approach would enhance the performance of the overall air-traffic control when dealing with an increasing number of airplanes [5].

The variables directly related to an airplane velocity within a section are (i) section length, (ii) section velocity established velocity limits within the section and (iii) airplane velocity - velocity limits the airplane may achieve.

The aim of this work is to provide smooth velocity increase or velocity reduction by using a fuzzy logic inference mechanism. The referred variables are fuzzified into linguistic terms that are combined into a set of fuzzy rules. Input variables are the section length, the section velocity, and the airplane velocity. The output variable is the rate of increase or the rate of reduction of the velocity [7].

The fuzzy variables as well as the set of inference rules are detailed next. The before mentioned variables may be adjusted according to the universe of discourse, the range of the membership functions, and the fuzzy rules defined according to pre-defined standards of air-traffic control practices.

\section{A. Input variables and linguistic terms}

The variables related to air-traffic control employ the following linguistic terms: $D S$ (distance in the section), $V S E C$ (velocity section), and $A V$ (airplane velocity). 
The range of the universe of discourse for the $D S$ linguistic variable corresponds to the determined distance in the section and for the VSEC and $A V$ variables the universe of discourse is related to the pre-programmed minimum and maximum velocities. The following linguistic terms are used to characterize the $D S$ variable: $V S$ (very small), $S M$ (small), $M E$ (mean), $B I$ (big), and $V B$ (very big). In order to illustrate it, for a 9 nautics miles long section, 4.5 miles correspond to the $M E$ concept, and 0.9 nautics miles may be considered to be between $V S$ and $S M$ (Fig. 4).

The terms defined for the VSEC variable are related to the current airplane velocity in the air lane section when compared to the maximum velocities permitted at the entrance and exit points of the section. The linguistic terms are named: $V L V$ (very low velocity), $L V$ (low velocity), $M V$ (mean velocity), $H V$ (high velocity), $V H V$ (very high velocity). The $M V$ term was established as the maximum velocity to be achieved at the section exit point (Fig. 5). Equation (1) relates $V H V$ and $V L V$ with $M V$ and, thus, defines the universe of discourse for $V S E C$.

$$
V L V=M V-(V H V-M V)
$$

It is worth mentioning that previous definitions do not take into account the possibility of an airplane to achieve a velocity very different from the limits stated by the aircontrol center, thus diverging from the universe of discourse. In practice, however, there are no constraints upon the airplane velocity be higher that those ( $V L V$ and $V H V)$ established for a specific lane, for a particular section. It means that the universe of discourse in Fig. 5 should adapt according to the maximum velocity an airplane is able to perform. In order to overwhelm this problem this paper also includes an adaptive mechanism for the decision-making generating, thus, an adaptive fuzzy decision support system. For instance, the new membership functions related to Fig. 5 may acquire the configuration shown in Fig. 6. In doing so, $M V$ keep on representing the ideal velocity desired at the final section yet adapts to the airplane velocity available given by Vmin and Vmax.
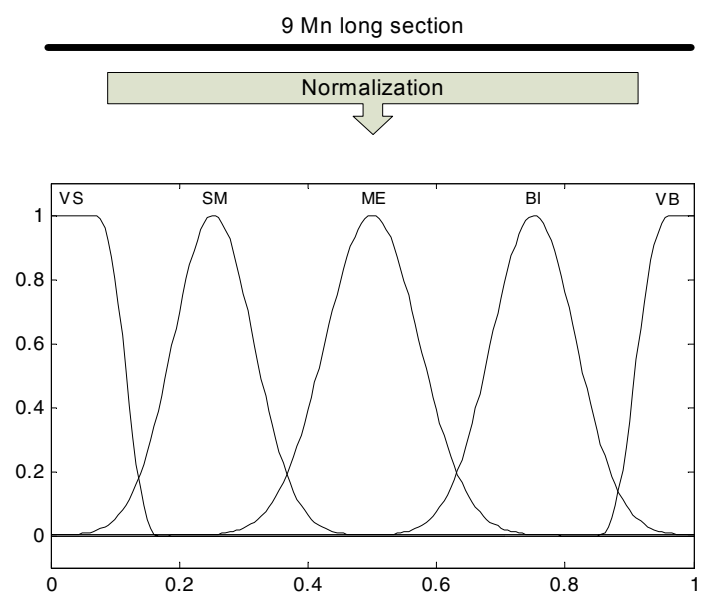

Fig. 4 Normalization process $-D S$ variable.

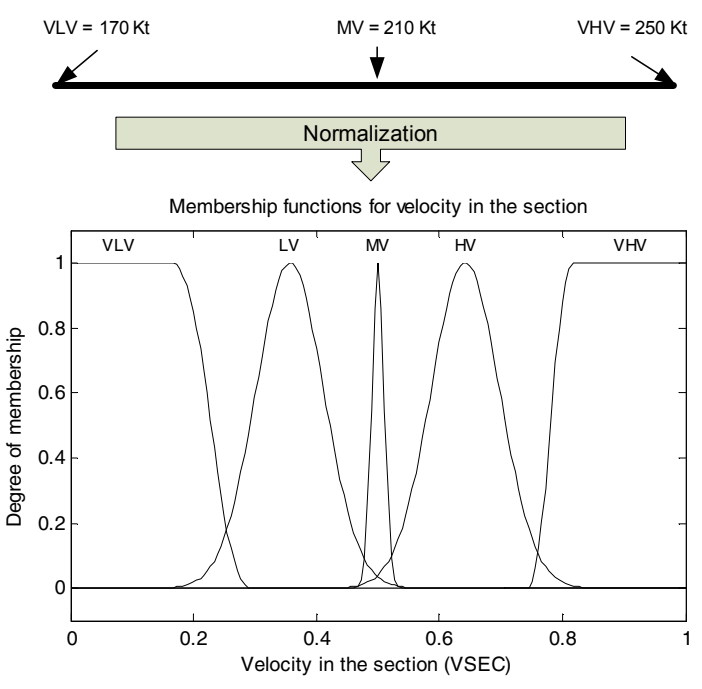

Fig. 5 Normalization and adaptation

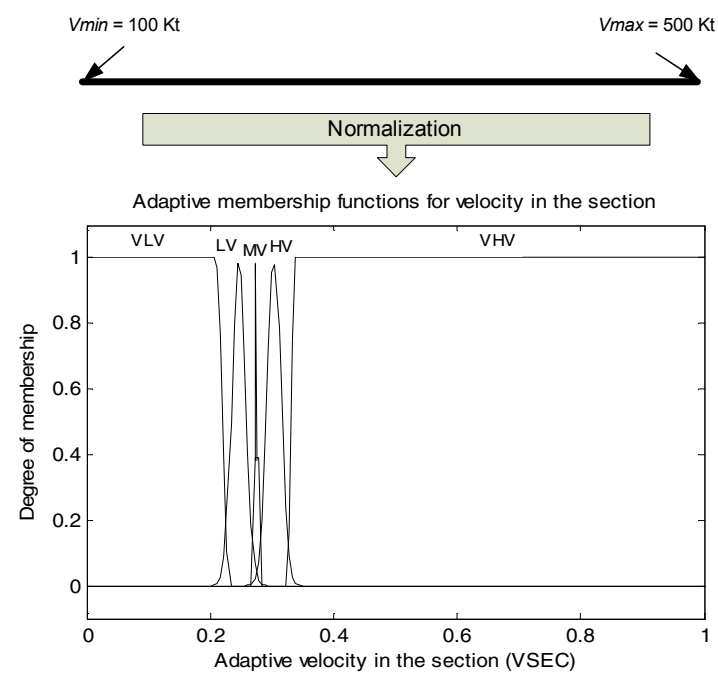

Fig. 6 Normalization and adaptation

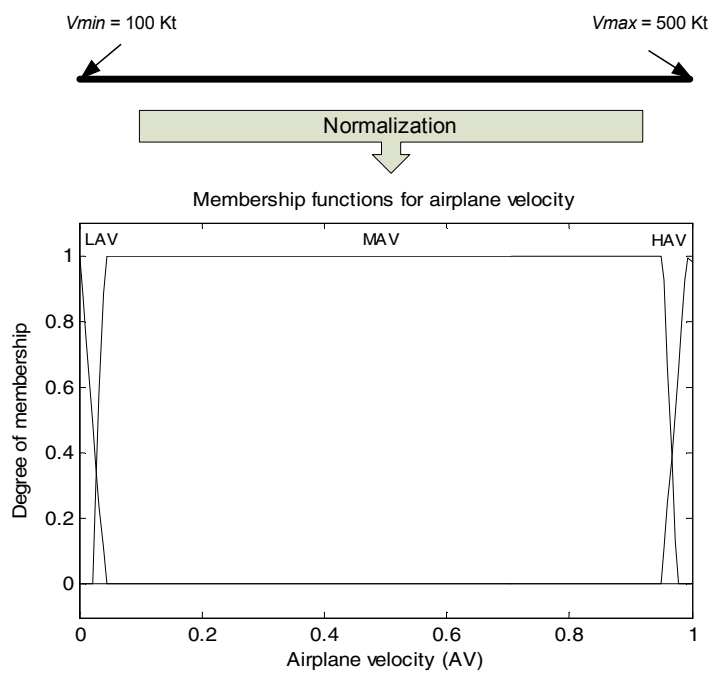

Fig. 7 Membership function for the $A V$ variable. 


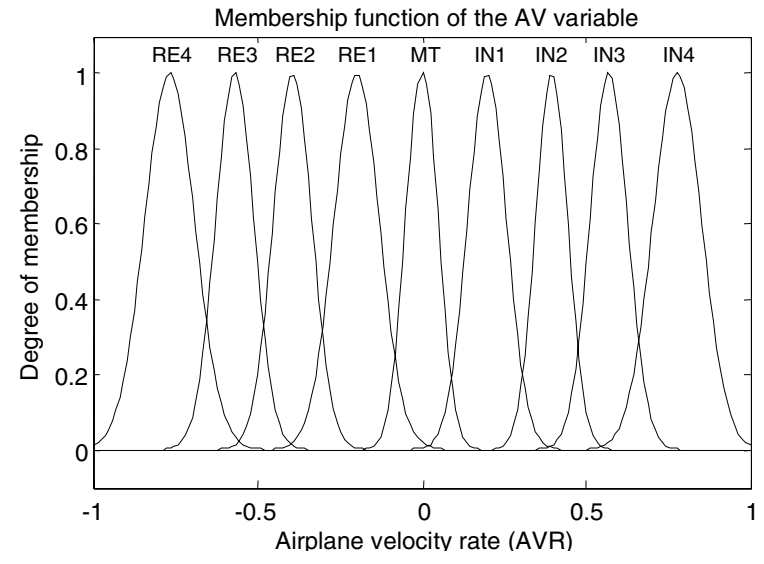

Fig. 8 Membership function for the $A V R$ variable.

The universe of discourse for the $A V$ linguistic variable is determined by the Vmin and Vmax that the airplane may achieve. The following terms are used: $L A V$ (low airplane velocity), $M A V$ (mean airplane velocity), and $H A V$ (high airplane velocity). The Fig. 7 shows the normalization of the $A V$ variable.

\section{B. Output variables and linguistic terms}

The output variable named airplane velocity rate $(A V R)$ provides velocity increase or velocity reduction rates an airplane should achieve. The universe of discourse is enclosed in the interval $[-1,+1]$, that is, it is normalized. The following terms are used: $M T$ (keep the velocity), IN1 to IN4 (different degrees of increase rate), and $R E 1$ to $R E 4$ (different degrees of reduction rate) (Fig. 8).

\section{Fuzzy rules}

The fuzzy rules used to obtain the $A V R$ output variable are given in Table 1. The inference mechanism is the Mamdani direct method that was chosen due the facility to mimic an operator and, thus, to be implemented for an intelligent agent [2]. In doing so, T-norm and T-conorm are chosen to be min and max, respectively. The velocity rate is related to the degree of fulfillment of each membership function, $\mu$ ( $D S, V S E C, A V$ ), employed in the set of rules. The final output value is computed through center-of-area defuzzification process.

As an example, consider that an airplane is at mean velocity $(M A V)$ as related to Vmin and Vmax, at high velocity $(H V)$ related to section's thresholds, and at a very small distance (VS). Then the output is a change in the velocity rate around the RE3 term. This rule is summarized as follows:

\section{IF $A V$ is $M A V$ and $V S E C$ is $H V$ and $D S$ is $V S$}

\section{THEN $A V R$ is $R E 3$.}

Nevertheless, the velocity rate needs to accommodate the velocity range an airplane may achieve. According to it, a new velocity rate, $T X$, must be determined. It should be computed not only as function of the degree of membership,
TABLE I

FUZZY RELATIONSHIP AMONG INPUT AND OUTPUT VARIABLES

$\underline{\text { LAV }}$

\begin{tabular}{|c|c|c|c|c|c|}
\hline & $V L V$ & $L V$ & $M V$ & $H V$ & VHV \\
\hline VS & IN3 & IN2 & IN1 & IN1 & IN1 \\
\hline$S M$ & IN2 & IN2 & IN1 & IN1 & IN1 \\
\hline$M E$ & IN2 & IN1 & IN1 & IN1 & IN1 \\
\hline BI & IN1 & IN1 & IN1 & IN1 & IN1 \\
\hline$V B$ & IN1 & IN1 & IN1 & IN1 & IN1 \\
\hline
\end{tabular}

MAV

\begin{tabular}{|c|c|c|c|c|c|}
\hline & $V L V$ & $L V$ & $M V$ & $H V$ & $V H V$ \\
\hline VS & IN4 & IN3 & MT & RE3 & RE4 \\
\hline & IN3 & IN2 & MT & RE3 & RE4 \\
\hline & IN2 & IN2 & MT & RE2 & RE3 \\
\hline$B$ & IN1 & IN2 & MT & RE2 & RE3 \\
\hline VB & IN1 & IN1 & MT & RE1 & RE2 \\
\hline
\end{tabular}

$\underline{\text { HAV }}$

\begin{tabular}{|c|c|c|c|c|c|}
\hline & $V L V$ & $L V$ & $M V$ & $H V$ & $V H V$ \\
\hline VS & MT & MT & MT & RE3 & RE4 \\
\hline$S M$ & MT & MT & MT & RE3 & RE4 \\
\hline$M E$ & MT & MT & MT & RE2 & RE3 \\
\hline BI & MT & MT & MT & RE2 & RE3 \\
\hline$V B$ & MT & MT & MT & RE1 & RE2 \\
\hline
\end{tabular}

$\mu(D S, V S E C, A V)$ but according to the maximum and minimum velocities, as well:

$$
T X=\frac{\mu(D S, V S E C, A V)}{(V \max -V \min )} .
$$

\section{MAIN RESULTS}

Some experiments were conducted leading to two analyses. Different airplane initial velocities were used to obtain partial velocities at $1 / 4,1 / 2,3 / 4$ of the section length and the end of the section, thus permitting to analyze the influence of the initial airplane velocity on the system to converge to the established section set point velocity (MV).

\section{A. Case Study 1}

The aim of this case study is to monitor the behavior of an airplane velocity control by considering a general airplane able to achieve the desired velocity in the section (MV). The characteristics established for this example are:

- Maximum (Vmax) and minimum (Vmin) velocities the airplane may achieve, respectively, are $800 \mathrm{Kt}$ and 80 $\mathrm{Kt}$;

- Maximum allowed velocities at the section entrance is $250 \mathrm{Kt}$ while at the end points is $210 \mathrm{Kt}$;

- Initial velocities ranges from $150 \mathrm{Kt}$ to $290 \mathrm{Kt}$; and

- Section length is 9 nautics miles.

During the simulation it is possible to observe that the control system works adequately by making the airplane to achieve the ideal section velocity set up at $210 \mathrm{Kt}$ (Fig. 9). The limitation of this approach is related to the proper constraints established for smooth flights. As it was expected, the control system does not converge to the desired 
set point when the airplane velocity is very low or very high because the section is very short to permit a smooth reduction in the velocity.

\section{B. Case Study 2}

This case study simulates the possibility the airplane presents physical constraints in achieving the desired velocity in the section (MV). For instance, the set point MV is chosen to be smaller than the minimum velocity the airplane supports (Vmin). It means that if the airplane reaches the desired velocity there is a lost in the powers of sustentation and balance in normal fight causing a crash. The parameters used in this example are:

- Maximum (Vmax) and minimum (Vmin) velocities the airplane are allowed to achieve are, respectively, $800 \mathrm{Kt}$ and $130 \mathrm{Kt}$;

- Maximum velocities at the entrance of the section is 150 Kt while at the exit is $120 \mathrm{Kt}(<130 \mathrm{Kt})$;

- Initial velocity ranges from $130 \mathrm{Kt}$ to $200 \mathrm{Kt}$,

- Section length is 9 nautics miles

In this example the velocities do not converge to the speed set up for the section, as expected. This problem comes up because the inferior velocity the airplane may perform is 130 $\mathrm{Kt}$ while the required velocity is $120 \mathrm{Kt}$ at end of the section. In spite of the fact the proposed fuzzy system leads the airplane to the closest velocity established as shown in Fig. 10 but avoiding an accident by respecting the physical limits of the aircraft.

\section{Case Study 3}

A case study opposite to the last one is simulated now. In this example the airplane is not capable of achieving the desired velocity in the section (MV) because it is greater than the maximum velocity allowed to the airplane. It means that the aircraft engine is not able to carry out the desired performance. The features used for this simulation are:

- Maximum (Vmax) and minimum (Vmin) velocities the airplane may achieve are, respectively, $200 \mathrm{Kt}$ and $50 \mathrm{Kt}$;

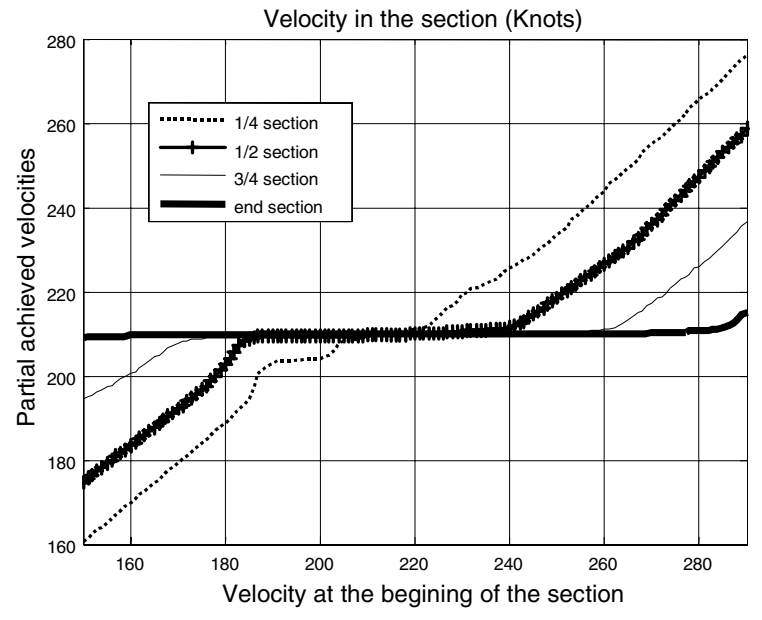

Fig. 9 Partial achieved velocities in the section

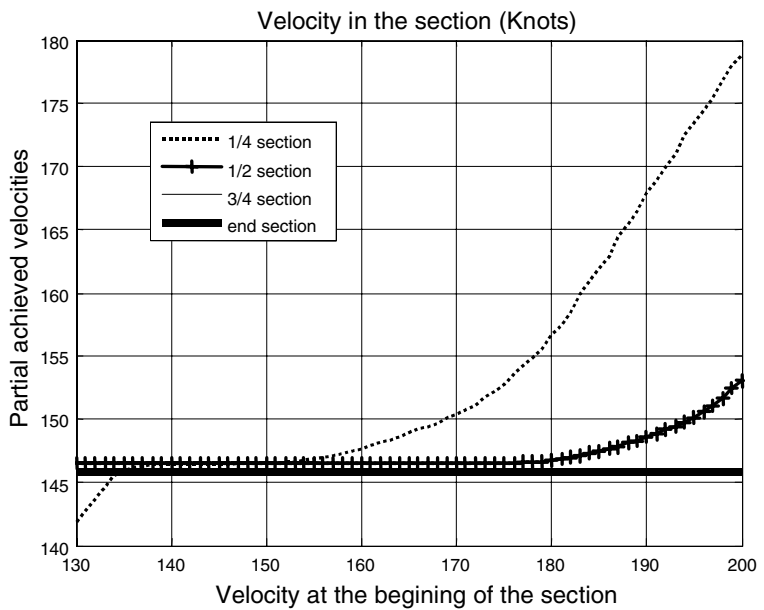

Fig. 10 Partial achieved velocities in the section.

- Maximum velocities at the entrance of the section is $250 \mathrm{Kt}$ while at the exit points is $210 \mathrm{Kt}$;

- Initial velocity ranges from $50 \mathrm{Kt}$ to $200 \mathrm{Kt}$,

- Section length is 9 nautics miles.

Results obtained in this case study are given in Fig. 11. Due to the superior velocity restriction, Vmax, imposed by the dynamical characteristics of the airplane, the convergence is not achieved ( $\mathrm{MV}=210 \mathrm{KT}$ ) for this example. It is possible to notice, however, that the proposed fuzzy system produced velocities for the airplane to approximate the closest the maximum velocity allowed for it. Again, it is worth to mention that the fuzzy system yields a velocity compatible both with the limits of the airplane as well as the velocity set up for the lane meanwhile does not cause a failure in the airplane engine system.

Preliminary results indicate that the proposed fuzzy system succeeded in constructing a decision support approach in this particular application for the established distinct operational conditions. It must be emphasized, however, that the set of rules and the membership functions were obtained through interview with specialists.

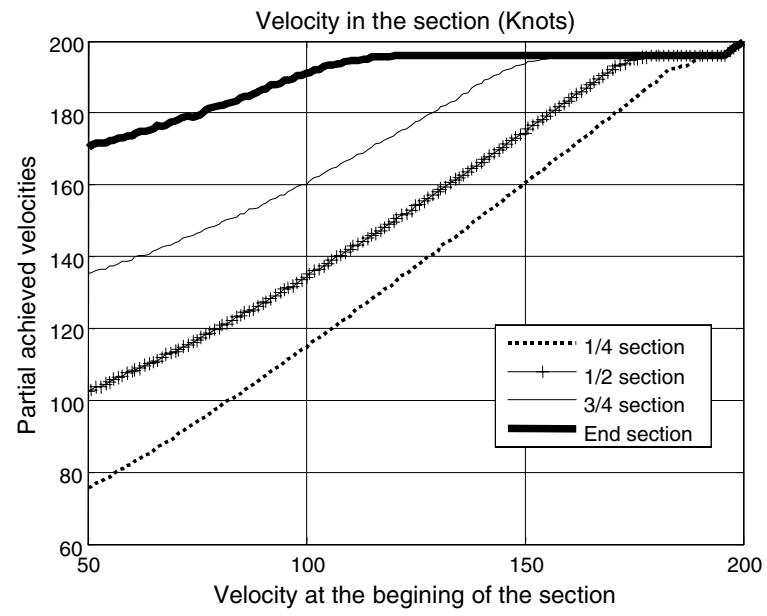

Fig. 11 Partial achieved velocities in the section 
Consequently, the fuzzy system was built in a heuristic manner and is not optimized. In this case, for instance, the overlapping areas between membership functions presents low crossover points that would work as a source of doubt in the inference mechanism. Despite the membership functions must be better tuned, in fact, these partial results show one of the advantages of employing fuzzy system: its inherent ability in dealing with uncertainties and imprecision. Moreover, new results were obtained by exchanging the membership functions from Gaussian to Bell functions creating crossover points at 0.7 instead of 0.2 as stated previously. While for the former response is more limited and abrupt (solid line) by employing the new membership functions results are smother (dashed line) (Fig. 12).

\section{CONCLUSION AND FUTURE WORKS}

This paper proposes a fuzzy decision support system (DSS) to make an airplane fly within the velocity limits established by air-traffic control centers when drifting into different sections as well as not to stray out of restrict areas not allowed when airplanes approach airports for landing.

Despite the elevate number of variables involved in airtraffic control in this paper results are encouraging and show that the use of fuzzy logic may be an alternative to help airtraffic controllers in monitoring heavy air-traffic by merging different information to enhance the performance scenarios.

The fuzzy system presented here demonstrated its effectiveness by obtaining satisfactory velocity rates for accelerating and slow down the aircraft and by accomplishing a speed convergence to the ideal flight velocity determined for each MV section, in most of the cases - though only three examples were presented here.

Future work must be carried out to verify the influence of parameters in obtaining an optimal fuzzy system for this particular purpose. Finally, it is worth mentioning that the proposed fuzzy system must be better studied since it deals with human lives. Nevertheless, results obtained showed that this approach has proved to be effective and is promising in helping air-traffic controllers in managing airports and airplanes.

\section{REFERENCES}

[1] Araujo, J.E., Kienitz, K.H. "Adaptive Reference - driven decision - making process", Proc. FUZZY- IEEE Inter. Conf. on Fuzzy Systems, St. Louis, Missouri, 2003, Vol. 1, pp. 452-457.

[2] Araujo, J.E., Kienitz, K.H., Sandri, S.A., Silva, J.D.S. "Fuzzy reference gain-scheduling approach as intelligent agents: FRGS agent”, Proc. FUZZY- IEEE Inter. Conf. on Fuzzy Systems, Budapest, Hungary, 2004, Vol. 3, pp. 1625-1630.

[3] B. N. Iordanova, "Air traffic knowledge management policy," European Journal of Operational Research, v.146, n.1, 2003, pp. 83-100.

[4] Becker JT, Milke RM.," Cognition and aging in a complex work environment: relationships with performance among air traffic control specialists." Aviat Space Environ Med. 1998 Oct;69(10):944-51.

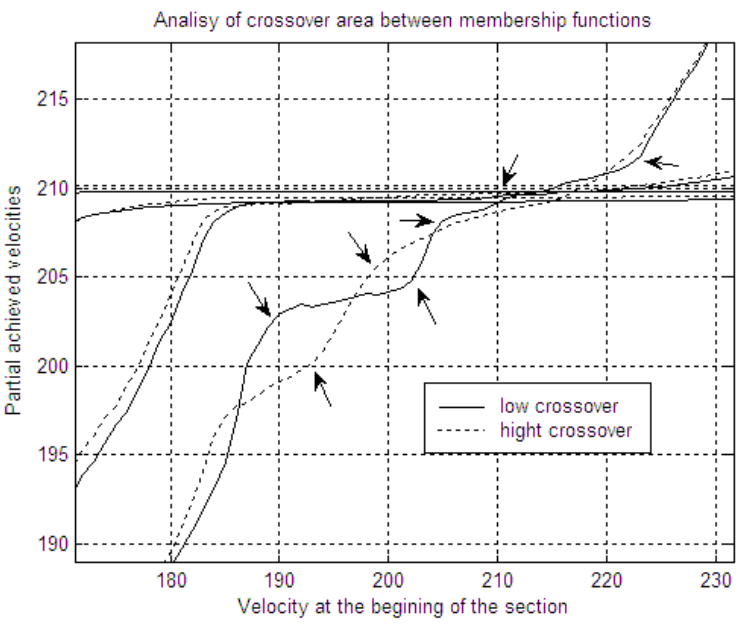

Fig. 12 Partial achieved velocities in the section

[5] C. Pusch, "Air traffic management", 2001, pp. 255-257.

[6] D. Jara, K. Corker, "Supervisory control: Air traffic control specialist performance in shared versus traded states", Proc. the Digital Avionics Systems Conference, 2002. v.1, 2002 pp. 2B2-1 - 2B2-10

[7] Essentials of fuzzy Modeling and control. Ronald R. Yager e Dimitar P. Filev. Editora: John Wiley \& Sons, Inc. Ano: 1994 USA.

[8] Fabry, J.M.; Lupinetti, A.A., "Applications of simulation and artificial intelligence technology for ATC training", Proceedings of the IEEE, v.77, n.11, 1989, pp.1762 - 1765.

[9] Fuzzy Sets, Decision Making and Expert Systems. Zimmermann. 1987

[10] J. Nogami, S. Nakasuka T. Tanabe, "Real-time decision support for air traffic management, utilizing machine learning", Control Engineering Practice, v.4, n.8., 1996, pp. 1129-1141.

[11] Kahne, S.; Frolow, I.; "Air traffic management: evolution with technology", Control Systems Magazine, IEEE, v.16, n.4, 1996 pp. $12-21$.

[12] L.A. Zadeh, "Fuzzy Sets", in Information and Control, v. 8, 1965, pp. 338-353.

[13] M. P. Pacaux-Lemoine, S. Debernard, "Common work space for human-machine cooperation in air traffic control", Control Engineering Practice, v.10, n.5, 2002, pp. 571-576.

[14] P. A. Leal de Matosa, P. L. Powell, "Decision support for flight re-routing in Europe", Decision Support Systems, v.34, n.4., 2003, pp. 397-412.

[15] P. L. de Matosa, R. Ormerod, "The application of operational research to European air traffic flow management understanding the context", European Journal of Operational Research, v.123, n.1, 2000, pp.125-144

[16] Spencer, A.; Smith, P.; Billings, C.; Brinton, C.; Atkins, S.; Walton, D.; "Decision support tools to assist in airport surface management", Proc. IEEE International Conference v.2, n.5-8, 2003, pp. $1606-1611$.

[17] T. Kontogiannis, Z. Kossiavelou, "Stress and team performance: principles and challenges for intelligent decision aids", v.33, n.3, 1999, pp.103-128.

[18] T. S. Perry, "In Search of the Future of Air Traffic Control", IEEE Spectrum, August, 1997.

[19] T.G. Reynolds, R.J. Hansman, "Conformance monitoring approaches in current and future air traffic control environments", Digital Avionics Systems Conference, 2002. Proceedings. The 21stv.2, 2002 Pp. 7C1-1 - 7C1-12 vol.2

[20] U. Metzger, R. Parasuraman, "The role of the air traffic controller in future air traffic management: an empirical study of active control versus passive monitoring", 2001 Winter;43(4):519-28. 